\title{
COMIC LEARNING MEDIA DEVELOPMENT IN EFFORTS TO GROW LITERACY CULTURE AND ENVIRONMENTAL CARE ATTITUDE FOR ELEMENTARY SCHOOL STUDENT
}

\section{Syifa' Lana, Rifqi Aulia Rahman, Rudi Danang Widodo, Siti Fatimah}

Universitas Sebelas Maret

stfatimah89@gmail.com

\section{Article History}

accepted 30/09/2018

approved 12/10/2018

published 30/10/2018

\section{Keywords}

Key words: Comic

Learning Media, Literacy

Culture, Environmental

Care Attitude.

\begin{abstract}
This research was aimed to describe the science comic design with the environmental care theme as a learning medium for developing the literacy culture and environmental care attitude for elementary school students. Research and Development ( $R$ $\& D$ ) approach was implemented by utilizing $4 D$ models which was limited to the Develop stage only. The comic media was reviewed and assessed by an expert of media, a linguist, an expert of material, and three elementary school teachers.. The data were collected by using observation technique and questionnaire. The results showed that the comic science media with the theme of environmental care can be used as a learning medium that can develop a culture of literacy and attitudes of environmental care in primary schools based on the contents of the curriculum standard 2013. The quality result of the assessment from the expert and the student response indicated a good category.
\end{abstract}

Social, Humanities, and Education Studies (SHEs): Conference Series https://jurnal.uns.ac.id/shes

p-ISSN 2620-9284 e-ISSN 2620-9292 


\section{PENDAHULUAN}

UNESCO (2007) menyatakan bahwa Pendidikan Lingkungan Hidup merupakan suatu proses yang bertujuan untuk menciptakan suatu masyarakat dunia yang memiliki kepedulian terhadap lingkungan dan peduli terhadap masalah-masalah yang terkait di dalamnya serta memiliki pengetahuan, motivasi, komitmen, dan keterampilan untuk bekerja, baik secara perorangan maupun kolektif dalam mencari alternatif atau memberi solusi terhadap permasalahan lingkungan hidup yang ada sekarang dan untuk menghindari timbulnya masalah-masalah lingkungan hidup baru. UndangUndang RI No. 32 tahun 2009 tentang perlindungan dan pengelolaan lingkungan hidup pasal 1 ayat 2 menyatakan bahwa perlindungan dan pengelolaan lingkungan hidup adalah upaya sistematis dan terpadu yang dilakukan untuk melestarikan fungsi lingkungan hidup dan mencegah terjadinya pencemaran dan/atau kerusakan lingkungan hidup yang meliputi perencanaan, pemanfaatan, pengendalian, pemeliharaan, pengawasan, dan penegakan hukum. Berdasarkan hal tersebut, menjaga lingkungan menjadi keharusan bagi manusia agar alam tetap terjaga dan terhindar dari kerusakan. Menurut OECD (2012: 1) mengungkapkan bahwa sekolah adalah sumber informasi penting tentang masalah lingkungan bagi siswa. Akan tetapi, di sebagian besar negara hanya sebagian kecil sekolah memiliki program yang di dedikasikan untuk lingkungan. Pada kenyataannya sikap peduli lingkungan khususnya di Indonesia masih sangat rendah. Hal ini dibuktikan dengan hasil survey Environmnet Protection Index atau Indeks Perlindungan Lingkungan tahun 2016 negara Indonesia menduduki peringkat ke 107 (http://banjarmasin.tribunnews.com). Dilanjutkan berdasarkan data Jenna Jambeck dari Univesity of Georgia menghasilkan temuan bahwa Indonesia berada di peringkat kedua dunia penghasil sampah plastik ke laut yang mencapai 187,2 juta ton. Menurut data yang dilansir oleh Dirjen Pengelolaan Sampah, Limbah, dan B3 KLHK total jumlah sampah mampu mencapai 68 juta ton pada tahun 2019, begitu juga sampah plastik yang diperkirakan mencapai 9,52 ton (http://nationalgeographic.co.id).

Tindakan setiap individu mempengaruhi lingkungan dan sekolah memainkan peran penting dalam membangun pengetahuan tentang masalah lingkungan yang sangat penting seperti: polusi udara, energi, kepunahan mahluk hidup(hewan dan tumbuhan), penggundulan hutan, kekurangan air serta limbah nuklir (OECD, 2012: 4). Pendidikan dapat menjadi salah satu upaya dalam meminimalisir terjadinya kerusakan lingkungan (Muspiroh.N, 2014). Hal ini dikarenakan melalui pendidikan tidak hanya mencerdaskan anak bangsa namun menanamkan karakter yang salah satunya adalah sikap peduli lingkungan. Penanaman sikap peduli lingkungan anak-anak di sekolah menjadi tanggung jawab yang besar bagi seorang pendidik. Salah satu cara menanamkan karakter sikap peduli lingkungan adalah dengan memberikan contoh nyata dalam kehidupan sehari-hari di lingkungan sekolah seperti membuang sampah di tempat sampah dan sesuai dengan jenis-jenis sampah. Selain itu, proses pembelajaran menjadi kegiatan yang paling penting dalam menanamkan sikap peduli lingkungan. Berdasarkan kurikulum 2013 di sekolah dasar, tema-tema dalam pembelajaran lebih banyak mengacu ke tema lingkungan. Seperti tema lingkungan bersih dan sehat di kelas 1, tema hidup bersih dan sehat di kelas 2, dan tema menjaga kelestarian lingkungan di kelas 3 , tema peduli terhadap makhluk hidup di kelas 4 , tema sehat itu penting di kelas 5 , dan selamatkan makhluk hidup di kelas 6 . Oleh sebab itu, setiap pembelajaran di SD harus memberikan dampak yang positif terhadap sikap peduli lingkungan anak didik.

Salah satu upaya pendidik dalam menanamkan karakter sikap peduli lingkungan dalam pembelajaran adalah dengan menggunakan media pembelajaran yang menarik seperti komik sehingga pembelajaran akan menyenangkan. Zaki (2008) menjelaskan 
bahwa media komik dapat digunakan sebagai salah satu bentuk alternatif media pembelajaran. Teknik penggunaan media komik adalah mengutamakan aktivitas komunikasi dan membaca dengan memperhatikan cerita bergambar sekaligus mempraktekkan percakapan yang telah tersedia, dengan demikian secara langsung maupun tidak langsung akan memunculkan potensi yang ada dalam diri siswa. Media pembelajaran komik memiliki peran yang strategis dalam menyampaikan ilmu untuk siswa di sekolah dasar. Hal ini dikarenakan, siswa sekolah dasar cenderung menyukai pada hal-hal yang berbentuk gambar dan cerita. Menurut Sudjana \& Rivai (2005: 65) dalam saputro, D.A. (2015:3) menyatakan bahwa buku-buku komik maupun gambar dapat dipergunakan secara efektif oleh guru-guru dalam usaha meningkatkan minat, mengembangkan pembendaharaan kata-kata dan keterampilan membaca. Melalui media pembelajaran komik, pembelajaran dapat lebih menyenangkan dan dapat memotivasi siswa dalam membaca dan menyerap materi/informasi. Berdasarkan hal tersebut, media komik dapat dijadikan sebagai media pembelajaran untuk menyampaikan informasi pendidikan lingkungan. Selain sikap peduli lingkungan yang dapat dikembangkan dalam pembelajaran menggunakan komik ini, budaya literasi dapat juga dikembangkan. Telah dipahami bersama bahwa UNESCO mencatat indeks minat baca di Indonesia yaitu baru mencapai 0,001. Artinya, pada setiap 1.000 orang, hanya ada satu orang yang punya minat membaca. Masyarakat di Indonesia rata-rata membaca nol sampai satu buku per tahun. Angka tersebut kian timpang saat disandingkan dengan warga Amerika Serikat yang terbiasa membaca 10-20 buku per tahun. Saat bersamaan, warga Jepang membaca 10-15 buku per tahun (Permatasari, 2015:148). Menurut OECD (2014) menyatakan bahwa literasi penting bagi siswa untuk mempersiapkan hidup mereka dalam dunia yang berubah cepat. Oleh sebab itu, media pembelajaran komik dapat dijadikan alternatif dalam menumbuhkan budaya literasi dan sikap peduli lingkungan anak didik SD.

Penelitian ini merupakan penelitian pengembangan (Research and Development) mengadaptasi pada pengembangan model Four-D yang dikemukakan oleh Thiagarajan, Semmel, dan Semmel (1974). Model ini terdiri dari 4 tahap pengembangan, yaitu Define, Design, Develop, and Disseminate. Produk penelitian berupa komik dengan tema peduli lingkungan untuk SD/MI kelas III sebagai sarana untuk meningkatkan budaya literasi dan sikap peduli lingkungan. Adapun alur pengembangan dalam penelitian seperti dalam gambar 1 . 


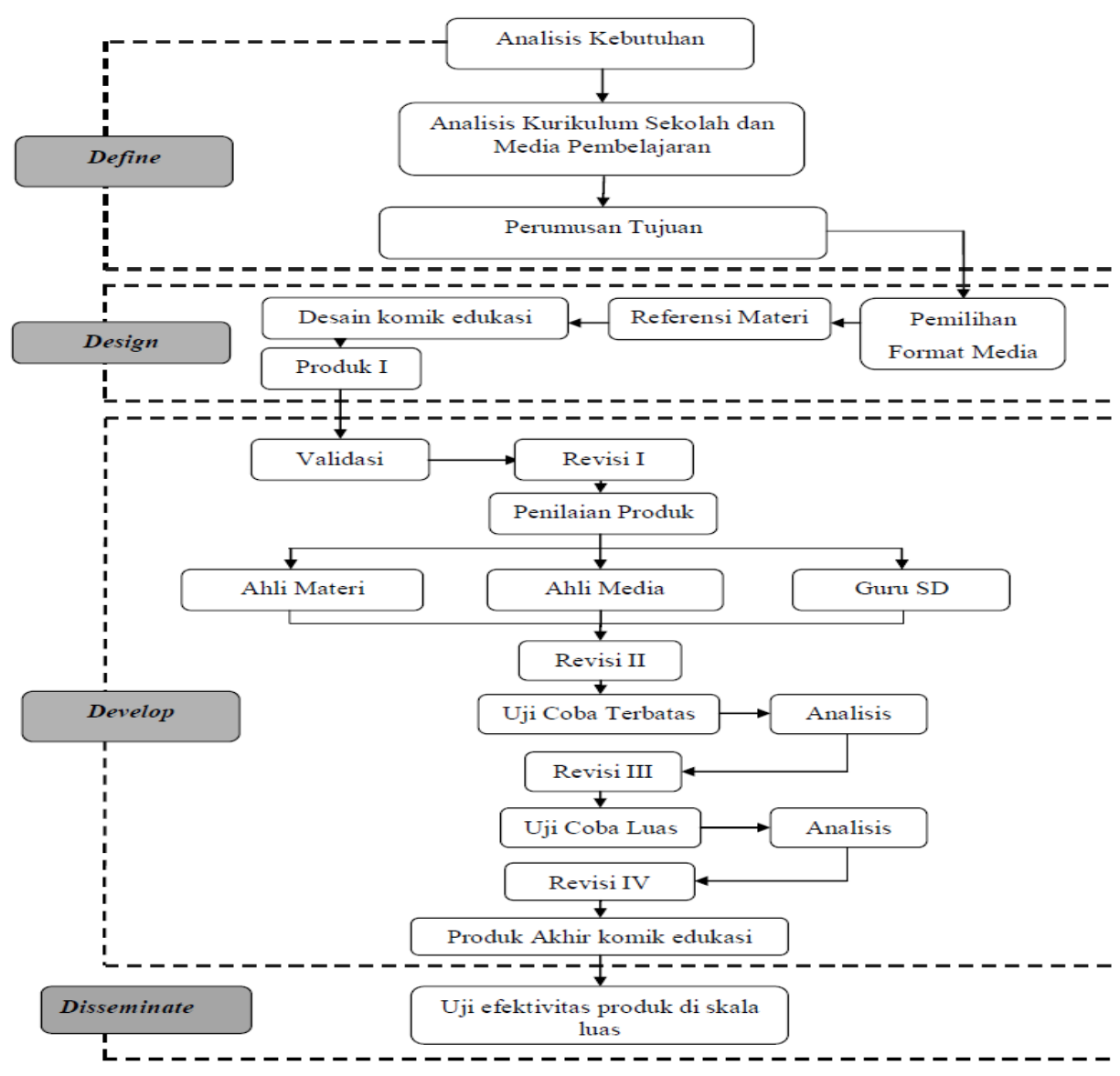

Gambar 1. Alur penelitian pengembangan model 4D

Instrumen yang digunakan adalah lembar angket dan lembar observasi. Teknik analisisdata menggunakan deskripti kualitatif dan dikategorikan seperti pada tabel 1 dan 2.

Tabel 1. Kategori penilaian produk oleh ahli

\begin{tabular}{cc}
\hline Rata-rata Skor $(\overline{\bar{X}})$ & Kategori \\
$>3,25-4,00$ & Sangat Baik (SB) \\
$>2,50-3,25$ & Baik (B) \\
$>1,75-2,50$ & Tidak Baik (TB) \\
$1,00-1,75$ & Sangat Tidak Baik (STB) \\
\hline \multicolumn{2}{c}{ (Diadaptasi dari Putro.E, $2012:$ 110) }
\end{tabular}

Tabel 2 Kategori penilaian produk oleh peserta didik

\begin{tabular}{cc}
\hline Rata-rata Skor $(\overline{\bar{X}})$ & Kategori \\
\hline $0,50-1,00$ & Baik \\
$0,00-0,50$ & Tidak baik \\
\hline
\end{tabular}

(Diadaptasi dari Putro.E, 2012: 123)

Kemudian, data yang diperoleh dihitung persentase keidealannya menggunakan persamaan 1.

Persentase keidealan $(\mathrm{p})=\frac{\text { skor hasil penelitian }}{\text { skor tertinggi ideal }} \times 100 \% \quad$....(pers. 1) 


\section{HASIL DAN PEMBAHASAN}

Telah berhasil dikembangkan produk media pembelajaran berdasarkan standar isi kurikulum 2013 dengan tema 9 yaitu menjaga kelestarian lingkungan untuk siswa kelas III SD. Tema dalam penelitian ini terdiri dari empat mata pelajaran, yaitu PPKn, Bahasai Indonesia, Penjasorkes, Seni Budaya dan Prakarya, dan Matematika. Produk ini dinilai oleh 2 ahli materi dan 3 guru SD. Respon siswa dilaksanakan di SD Bumirejo 01 Kebumen kelas III untuk uji terbatas, dan respon siswa seluruh kelas untuk uji coba luas. Tabel 1 adalah hasil penilaian ahli materi dan guru SD.

Tabel 3. Ringkasan penilaian komik oleh para ahli

\begin{tabular}{lcl}
\multicolumn{1}{c}{ Penilai } & Nilai Rerata Skor & Kategori \\
\hline Ahli Media & 3,06 & Baik \\
Ahli Materi & 3,00 & Baik \\
Guru SD & 3,00 & Baik \\
Rata-Rata & $\mathbf{3 , 0 2}$ & Baik \\
\hline
\end{tabular}

Berdasarkan tabel 3 dihasilkan rerata penilaian produk sebesar 3,02 oleh ahli media, ahli materi, dan guru dengan persentase keidealan sebesar 78,3\%.

Tabel 4. Ringkasan hasil respon siswa uji terbatas dan uji luas

\begin{tabular}{clcc}
\hline No & Keterangan & Nilai Rerata Skor & Kategori \\
\hline 1 & Uji Terbatas & 1,00 & Baik \\
2 & Uji Luas & 1,00 & Baik \\
& Rata-Rata & $\mathbf{1 , 0 0}$ & Baik \\
\hline
\end{tabular}

Tabel 4 menunjukkan bahwa respon siswa pada komik di uji terbatas masuk dalam kategori Baik dengan rerata 1,00 sedangkan respon siswa pada komik di uji luas masuk dalam kategori Baik dengan rerata 1,00.

Berdasarkan penilaian ahli materi, ahli media, guru, dan respon siswa dapat diketahui bahwa media pembelajaran komik dengan tema 9 dapat digunakan sebagai media pembelajaran di SD. Media komik selain menarik minat siswa untuk membaca karena alur cerita dan gambar-gambar yang menarik juga memberikan latihan-latihan yang mampu mengasah kemampuan siswa. Selanjutnya, dengan adanya arahan untuk membuat prakarya dari barang bekas dapat digunakan untuk mengasah kreativitas siswa. Arahan untuk membuat prakarya selain bertujuan untuk mengasah kreativitas anak juga agar memanfaatkan barang bekas menjadi barang yang memiliki nilai guna. 


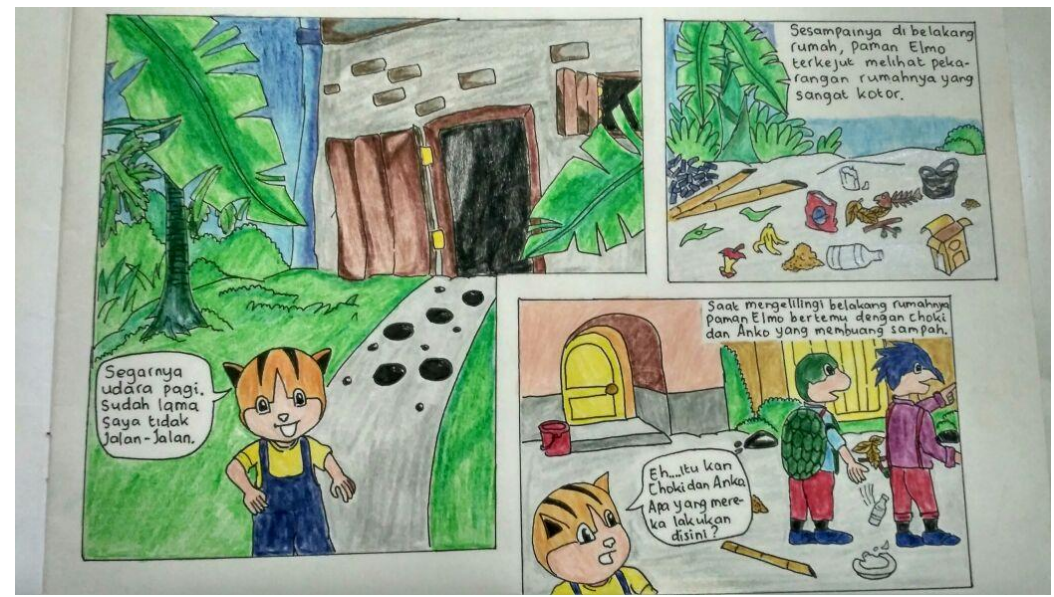

Gambar 2. Desain Komik Tema Lingkungan

Gambar 2 adalah salah satu contoh desain komik yang telah dikembangkan. Komik ini disesuaikan dengan desain komik sains Kuark yang telah banyak beredar dan sebagai bahan bacaan bagi kalangan siswa dan guru di Indonesia. Komik dengan tema 9 dapat dijadikan sebagai alternatif media pembelajaran yang inovatif dalam mewujudkan budaya literasi dan sikap peduli lingkungan.

Hal ini sejalan dengan penelitian Mardiyah,D.A. (2016) yang menjelaskan bahwa media komik memiliki dampak terhadap sikap peduli lingkungan dan kemampuan bernalar siswa. Setyawati,T.S dkk (2016) menyatakan melalui komik dapat menanamkan sikap peduli lingkungan dan meningkatkan kreativitas siswa. Menurut Sari,N dan Prodjosantoso (2018) menjelaskan bahwa pembelajaran IPA menggunakan komik lebih efektif dibandingkan pembelajaran tanpa menggunakan media pembelajaran komik. Media pembelajaran komik efektif untuk meningkatkan prestasi belajar siswa pada aspek kognitif. Melalui komik, siswa akan lebih antusias dalam membaca sehingga dapat menumbuhkan budaya literasi. Hal ini dikarenakan tampilan komik yang dibuat menarik baik dalam layout, pewarnaan, dan penyajian materi. Sari, Y (2017) menjelaskan bahwa melalui penggunaan bahan ajar komik melatih siswa untuk tidak hanya menerima sebuah materi tetapi mampu menemukan konsep-konsep melalui membaca dan mengikuti alur cerita yang terdapat dalam komik. Sehingga mampu meningkatkan prestasi belajar siswa.

\section{SIMPULAN}

Berdasarkan hasil analisis dapat disimpulkan bahwa telah dikembangkan produk berupa media pembelajaran komik pada tema peduli lingkungan untuk siswa SD/MI. Selanjutnya, produk berupa media pembelajaran komik pada tema peduli lingkungan untuk siswa SD/MI ini dinilai oleh 1 ahli media, 1 ahli materi, dan 1 guru menghasilkan kriteria kualitas Baik (B) dengan presentase sebesar 78,3\%. Uji terbatas dilakukan oleh 10 siswa dan menghasilkan kriteria Baik (B) dengan presentase sebesar 100\%. Sedangkan pada siswa di uji luas dilakukan oleh 20 siswa menghasilkan kriteria Baik (B) dengan presentase 100\%. Komik peduli lingkungan diharapkan dapat disebarluaskan ke sekolah yang lebih banyak agar dapat diketahui bahwa komik peduli lingkungan ini dapat dijadikan sumber bacaan bagi siswa SD/MI. 
DAFTAR PUSTAKA

Azhar. (2016). Setelah China, Indonesia Tempati Posisi Kedua Penyumbang Sampah Terbesar di Dunia. Diakses dalam http://nationalgeographic.co.id/berita/2016/07/setelah-cina-indonesia-tempatiposisi-kedua-penyumbang-sampah-terbesar-di-dunia

Mardiyah, D.A. (2016). Pengembangan Media Komik Pembelajaran untuk Meningkatkan Penalaran dan Dampaknya Terhadap Sikap Peduli Lingkungan pada Konsep Pencemaran Lingkungan di SMP. Thesis: UPI.

Muspiroh, N. (2014). Peran Pendidikan Islam dalam Pelestarian Lingkungan. Journal of Empirical Research in Islamic Education. Vol 2 (2): 129-151.

No Name. (2017). Finlandia, Negara Paling Bersih, Indonesia Peringkat 107. Diakses dalam http://banjarmasin.tribunnews.com/2017/07/19/finlandia-negara-palingbersih-indonesia-peringkat-107?page $=2$

OECD. (2012). How "Green" Are Today's 15-Years-Old?. PISA: OECD Publishing.

OECD.(2014). PISA Scientific Literacy: A Short Guide For Key Stage 4 Teachers. PISA: OECD Publisihing.

Permatasari, A. (2015). Membangun Kualitas Bangsa Dengan Budaya Literasi. Prosiding Seminar Nasional Bulan Bahasa UNIB hal 146-155.

Putro, E. (2012). Teknik Penyusunan Instrumen Penelitian. Yogyakarta: Pustaka Pelajar.

Saputro, D.A. (2015). Aplikasi komik sebagai media pembelajaran. Jurnal MUADDIB. Vol 05 (1): 1-19.

Sari, N \& Prodjosantoso. (2018). Pengembangan Media Komik IPA Model Inkuiri Terbimbing untuk Meningkatkan Aspek Kognitif Peserta Didik SMP. Jurnal Elementary. Vol 1 (1): 5-10.

Sari,Y. (2017). Pengembangan Bahan Ajar Komik IPA dengan Penanaman Nilai Budaya pada Siswa Kelas IV Sekolah Dasar. JSPD. Vol 3 (2): 129-142.

Setyawati,T.S, dkk. (2016). Pengembangan Komik IPA Berbasis PAIKEM untuk Menanamkan Sikap Peduli Lingkungan dan Mengembangkan Kreativitas Siswa. Jurnal Pendidikan Ilmu Pengetahuan Alam.I 4 (9): 24-31.

Thiagarajan,S., Semmel, D.S \& Semmel, M.L. (1974). Instructional Development for Training Teachers of Exceptional Children. Minneapolis, Minnesota: Leadership Development For Training Institute/Special Education, University Of Minnesota.

UNESCO. (2007). The UN Decade of Education for Sustainable Development, The First Two Years. Paris: UNESCO.

Zaki, G. 2008. Penggunaan Media Komik di dalam Pembelajaran Qiro'ah. Skripsi: UIN Sunan Kalijaga Yogyakarta. 